\title{
Incorporating foot assessment in the comprehensive geriatric assessment
}

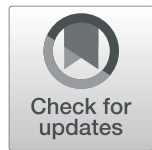

Rebecca K. Iseli ${ }^{1} 2^{*}$ DD, Gregory Duncan ${ }^{3}$, Elton K. Lee ${ }^{1}$, Ellen Lewis ${ }^{4}$ and Andrea B. Maier ${ }^{1,5,6}$

\begin{abstract}
Background: Foot problems are common in older adults and associated with poorer physical function, falls, frailty and reduced quality of life. Comprehensive Geriatric Assessment (CGA), a multidisciplinary process that is considered the gold standard of care for older adults, does not routinely include podiatry assessment and intervention in hospitalized older adults.

Aims: To introduce foot assessment to inpatient CGA to determine prevalence of foot disease, foot disease risk factors and inappropriate footwear use, assess inter-rater reliability of foot assessments, determine current podiatry input and examine associations between patient characteristics and foot disease risks.
\end{abstract}

Methods: Prospective, observational cohort study of older adults on geriatric rehabilitation wards. Foot assessment completed using the Queensland Foot Disease Form (QFDF) in addition to routine CGA.

Results: Fifty-two patients (median age [inter-quartile range] 86.4 [79.2-90.3] years, 54\% female) were included. Six patients (12\%) had foot disease and $13(25 \%)$ had a 'high risk' or 'at risk' foot. Foot disease risk factor prevalence was peripheral arterial disease 9 (17\%); neuropathy 10 (19\%) and foot deformity 11 (22\%). Forty-one patients (85\%) wore inappropriate footwear. Inter-rater agreement was substantial on presence of foot disease and arterial disease, fair to moderate on foot deformity and fair on neuropathy and inappropriate footwear. Eight patients (15\%) saw a podiatrist during admission: 5 with foot disease, 1 'at risk' and 2 'low risk' for foot disease. Patients with an at risk foot or foot disease had significantly longer median length of hospital stay (25 [13.7-32.1] vs 15.2 [8-22.1] days, $p=$ 0.01 ) and higher median Malnutrition Screening Test scores (2 [0-3] vs 0 [0-2], $p=0.03$ ) than the low-risk group. Patients with foot disease were most likely to see a podiatrist $(p<0.001)$.

Conclusion: Foot disease, foot disease risk factors and inappropriate footwear are common in hospitalized older adults, however podiatry assessment and intervention is mostly limited to patients with foot disease. Addition of routine podiatry assessment to the multidisciplinary CGA team should be considered. Examination for arterial disease and risk of malnutrition may be useful to identify at risk patients for podiatry review.

Keywords: Foot, Foot diseases, Aged, Geriatric assessment

\footnotetext{
* Correspondence: rebecca.iseli@mh.org.au

1Department of Medicine and Aged Care, @AgeMelbourne, The Royal

Melbourne Hospital, The University of Melbourne, Melbourne, Victoria, Australia

${ }^{2}$ Faculty of Pharmacy and Pharmaceutical Sciences, Monash University, Parkville, Australia

Full list of author information is available at the end of the article
}

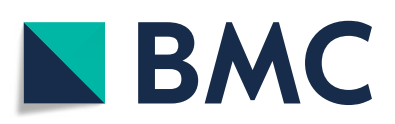

(0) The Author(s). 2021 Open Access This article is licensed under a Creative Commons Attribution 4.0 International License, which permits use, sharing, adaptation, distribution and reproduction in any medium or format, as long as you give appropriate credit to the original author(s) and the source, provide a link to the Creative Commons licence, and indicate if changes were made. The images or other third party material in this article are included in the article's Creative Commons licence, unless indicated otherwise in a credit line to the material. If material is not included in the article's Creative Commons licence and your intended use is not permitted by statutory regulation or exceeds the permitted use, you will need to obtain permission directly from the copyright holder. To view a copy of this licence, visit http://creativecommons.org/licenses/by/4.0/. The Creative Commons Public Domain Dedication waiver (http://creativecommons.org/publicdomain/zero/1.0/) applies to the data made available in this article, unless otherwise stated in a credit line to the data. 


\section{Introduction}

Changes to the feet occur with age, leading to high prevalence of foot problems such as foot pain, deformity, muscle weakness and reduced range of motion $[1,2]$. This contributes to morbidity in older populations: foot problems have been associated with a higher risk of falls [3], reduced quality of life [4-7], frailty [8] and lower independence in activities of daily living (ADLs) $[9,10]$. Lower independence in ADLs is associated with nursing home admission [11-13]. Poor foot care may also be an indicator of self-neglect $[14,15]$. Inappropriate footwear is associated with impaired balance with associated risk of falling [16] and foot disease [17]. Foot disease, defined as foot ulceration, infection, critical ischaemia and Charcot neuroarthropathy [18], represents more severe foot pathology. Foot disease is associated with many chronic illnesses and increases in prevalence with age [2, 19], affecting approximately $10 \%$ of hospital inpatients $[1,20]$. Foot disease usually occurs in people with risk factors such as foot deformity, peripheral arterial disease, peripheral neuropathy, previous ulceration and/or previous amputation [21]. In community dwelling older adults the presence of foot disease is associated with poorer physical function [22].

Despite the impact of foot problems and foot disease on older adults, the foot is frequently neglected by both patients and healthcare providers [23, 24]. The gold standard of care for older adults is the Comprehensive Geriatric Assessment (CGA), a multidimensional, multidisciplinary assessment of medical, social, psychological and functional needs that leads to the development of a coordinated care plan [25]. Podiatry interventional studies have shown reduced risk of falls in community dwelling older adults [26], and integration of a podiatry assessment in the CGA is recommended as part of falls assessment and prevention programs [27]. Inpatient CGA programs, on the other hand, do not routinely include podiatry assessment $[28,29]$.

The aim of this study was to introduce a standardised foot assessment to older adults undergoing inpatient CGA, to: (1) determine the prevalence of foot disease, foot disease risk factors and inappropriate footwear use;

(2) assess the inter-rater reliability of foot assessments;

(3) determine the frequency of podiatry assessment; and

(4) evaluate associations between patient characteristics and foot disease and foot disease risk factors.

\section{Methods}

\section{Study design}

\section{Population}

This study is embedded in REStORing health of acutely unwell adulTs (RESORT), an ongoing prospective, observational, longitudinal inception cohort investigating the characteristics and outcomes of geriatric rehabilitation patients at the Royal Melbourne Hospital (Melbourne, Victoria, Australia). Patients included in the RESORT study are assessed within $48 \mathrm{~h}$ of admission and discharge with a multidisciplinary, multi-dimensional CGA. Recruitment for wave 1 of RESORT commenced on October 15, 2017. Each annual RESORT wave recruits approximately 600 patients. This sub study, a pilot study adding foot assessment during the geriatric rehabilitation admission, recruited a convenience sample of inpatients from wave 3 between February 12 and March 19, 2020. A power calculation of sample size for foot disease prevalence was 138 patients (based on estimated prevalence of $10 \%, \mathrm{Z}$ statistic of 1.96 and allowable error of 0.05) [30]. This study was planned to run for 3 months, with an expected sample size of approximately 200 patients, however due to the COVID-19 pandemic recruitment ceased early. Patients were excluded from this study if they were receiving palliative care at admission, transferred to acute care prior to consenting to the study, unable to provide informed consent with no nominated proxy or were discharged prior to foot assessment. The study was performed in accordance with the Declaration of Helsinki and approved by the Melbourne Health Human Research and Ethics Committee (HREC) (approval number 2017.085).

\section{Patient characteristics}

Patient demographics, reason for admission and history of falls were collected from medical records and patient surveys. Physical function was assessed with the Functional Ambulation Classification [31], a scale from 0 to 5 recording ambulation ability, and the Short Physical Performance Battery (SPPB) [32], a three component assessment, scored from 0 to 12 points, of balance, 4-m walk and a chair stand test. Functional status was assessed using Katz Activities of Daily Living [33], a 6 item scale of independence in personal ADLs, and Instrumental Activities of Daily Living [34], a measure of independence in domestic and community ADLs, scored from 0 to 8 . For the ADL and mobility assessments higher scores indicate greater independence and better physical function, respectively. Nutritional status was assessed with the Malnutrition Screening Tool (MST): a score of 2 or more indicates risk of malnutrition [35]. Pressure injury risk assessment was undertaken using the Braden Scale, which evaluates six domains to determine risk score: scores below 18 suggest increased risk of pressure injury [36]. Medical co-morbidity was assessed with the Cumulative Illness Rating Scale (CIRS) [37], a measure that rates disease burden across major organ groups (higher scores indicating greater severity). Frailty was assessed using the Clinical Frailty Scale, a 7point scale, with higher scores indicating greater frailty [38]. Discharge destination (community or residential 
aged care facility) and death during geriatric rehabilitation admission were recorded from the medical history.

\section{Foot risk factors and foot disease assessment}

Assessment for foot disease and foot disease risk factors was undertaken by trained clinical researchers using the Queensland Foot Disease Form (QFDF), a 57 item, validated assessment instrument [18] (Additional file 1: Appendix I). The QFDF collects data on demographics, medical co-morbidities, foot disease risk factors and foot disease. Foot disease is defined as foot ulceration, infection, critical arterial disease (toe pressure of $<30 \mathrm{mmHg}$ or Ankle Brachial Index $<0.5$ ) and/or Charcot neuroarthropathy. Foot disease risk factors are deformity (defined as a score of 3 or more on a 6-point scale of deformity), peripheral neuropathy, peripheral arterial disease (toe pressure $<70 \mathrm{mmHg}$ ), previous ulceration and previous amputation. Footwear most commonly used indoors and outdoors was classified as appropriate or inappropriate. Inappropriate footwear was defined as footwear that does not have the following components: low heel, non-slip sole, supported heel collar or fastening mechanism [39]. The QFDF assigns a level of foot risk based on presence of foot disease risk factors: low (no neuropathy or PAD), at risk (neuropathy or PAD), high risk (foot deformity with neuropathy and/or PAD; previous foot disease) or acute foot disease.

Standardised training in use of the QFDF was undertaken with the assistance of a podiatrist (EL). A sample of foot assessments was repeated by the second assessor, blinded to the initial assessment, to check inter-rater reliability. The patient's treating team was notified of the outcome of the foot assessment where previously unidentified foot disease was noted, and recommendation for podiatry referral was made where appropriate. A number of patients also underwent foot assessment by a podiatrist as part of their usual care; this was recorded with the hospital podiatry assessment tool (Additional file 1: Appendix II). Referrals to podiatry were made by clinical staff as needed, usually by nursing staff based on skin assessments. The hospital podiatry assessment tool includes similar data to the QFDF; however, diagnosis of foot deformity and type of footwear are recorded by the podiatrist descriptively rather than using a prescribed format as with the QFDF.

Inter-rater reliability was assessed using percentage agreement overall and Cohen's Kappa co-efficient was calculated for 5 patients comparing researcher assessments and 8 patients comparing researcher to hospital podiatrist assessment. Agreement based on Kappa values was defined as: $\geq 0.8$ excellent; $0.61-0.80$ substantial; $0.41-0.6$ moderate and $<0.40$ fair to poor $[40,41]$.

Assessments were captured on paper forms and then de-identified and managed using the Research Electronic
Data Capture (REDCap) [42] tool. Data was exported to SPSS for Windows version 26 (IBM Corp. Released 2016. IBM SPSS Statistics for Windows, Version 24.0. Armonk, NY: IBM Corp) for analysis.

\section{Statistical analysis}

Descriptive statistics were used to summarise the patients' baseline characteristics. Data with a normal distribution is presented as mean and standard deviation; data with a non-normal distribution is presented as median and interquartile range; and categorical variables are presented as proportions. The baseline characteristics of the foot risk groups were compared using the Kruskal-Wallis $\mathrm{H}$ test (for more than 2 groups) or Mann-Whitney U test (for 2 groups) for nonparametric continuous and ordinal data and Fisher's exact test for categorical data. To reduce type 1 error, the level of significance for all analyses was set at $p<0.05$.

\section{Results}

The baseline characteristics of the 52 included patients are given in Table 1: median age was 86.4 [IQR 79.290.3] years, $54 \%$ were female. The median values for admission Katz ADL, iADL, SPPB, FAC and CFS demonstrate low independence, impaired mobility and moderate frailty in the cohort. A majority of patients (69\%) had fallen in the last year. Diabetes mellitus was diagnosed in $15(29 \%)$ patients.

\section{Foot disease, foot disease risk factors and inappropriate footwear}

Six patients (12\%) had foot disease (pressure injury (4/6), neuroischaemia (1/6) and trauma (1/6)). The prevalence of foot disease risk factors was: mild to moderate

Table 1 Characteristics of included geriatric rehabilitation inpatients at admission

\begin{tabular}{ll}
\hline Characteristic & $\mathbf{N = 5 2}$ \\
\hline Age, years & $86.4[79.2-90.3]$ \\
Female, $n(\%)$ & $28(54)$ \\
Falls in last 12 months, $n(\%)$ & $35(69)(n=51)$ \\
Number of falls in past year & $2[1-3.5]$ \\
Functional Ambulation Classification & $3[0.8-3](n=50)$ \\
Standardised Physical Performance Battery & $2[0-5](n=50)$ \\
Katz ADL & $2[1-3]$ \\
Instrumental ADL & $1[1-2.8]$ \\
Malnutrition Screening Tool & $1[0-2](n=51)$ \\
Braden score & $18[16-20]$ \\
Cumulative IIIness Rating Scale & $1.9[1.5-2.3]$ \\
Clinical Frailty Scale & $6[4-7](n=47)$ \\
\hline
\end{tabular}

Data are presented as median [IQR] unless otherwise stated $A D L$ Activities of Daily Living 
peripheral arterial disease 9 (17\%), neuropathy 10 (19\%) and foot deformity 11 (22\%). Reported footwear was inappropriate in 41 patients $(85 \%, n=48)$ : the most commonly worn footwear indoors and outdoors was slippers (34\%) and moccasins (33\%) respectively. Thirteen (25\%) patients were assessed as having an 'at risk' or 'high risk' foot. Eight patients (15\%) saw a podiatrist during their hospital admission: 5 had foot disease, 1 was at risk and 2 were low risk of foot disease. All patients that were seen by a podiatrist required an intervention, which included advice, nail care, debridement and wound dressings.

\section{Patient characteristics with and without foot disease}

Differences between patients based on risk foot or foot disease are summarised in Table 2. Patients with foot disease were significantly more likely to have podiatry assessment during hospitalisation. There was a trend towards an association between age and foot risk ( $p=$ 0.08 ). When risk category was dichotomised (low risk patients versus at risk, high risk and foot disease patients), patients with higher foot risk or foot disease had significantly longer median length of hospital stay (25 [13.7-32.1] vs 15.2 [8-22.1] days, $p=0.01$ ) and higher median MST scores $(2[0-3]$ vs $0[0-2], p=0.03)$ than the low-risk group.

\section{Inter-rater reliability}

There was substantial to excellent agreement on presence of foot disease (Cohen's kappa 0.75-1; percentage agreement 92\%), moderate to substantial agreement on presence of arterial disease (Cohen's kappa 0.5-1; percentage agreement 92\%), fair to moderate agreement on foot deformity (Cohen's kappa 0.33-0.5, percentage agreement 63\%) and fair agreement on neuropathy (Cohen's kappa 0-0.3, percentage agreement 63\%) and inappropriate footwear (Cohen's kappa 0-0.2, percentage agreement $67 \%$ ).

\section{Discussion}

Foot disease risk factors and foot disease were common in this cohort. Podiatry assessment and intervention was undertaken for most patients with foot disease but for few patients with an at risk or low risk foot. Inter-rater reliability testing confirmed that there was substantial agreement on presence of foot disease and arterial disease, however agreement was poorer for neuropathy, deformity and inappropriate footwear. Presence of peripheral arterial disease may therefore be a useful indicator for podiatry referral for patients with an at risk foot. Inter-rater reliability for footwear and neuropathy may have been impacted by high rates of cognitive

Table 2 Patient characteristics stratified by foot disease risk

\begin{tabular}{|c|c|c|c|c|c|}
\hline & Low risk $(n=33)$ & At risk $(n=6)$ & High risk $(n=7)$ & Foot Disease $(n=6)$ & $P$ value \\
\hline Age, years (median [IQR]) & $84.5[78.5-89.5]$ & 80.1 [63.9-89.9] & $90[87.4-92.1]$ & $89.1[85.7-93.1]$ & $0.08^{\#}$ \\
\hline Female, n (\%) & $20(61)$ & $2(33)$ & $3(43)$ & $3(50)$ & $0.59 \wedge$ \\
\hline Falls in last 12 months, n (\%) & $23(70)$ & $2(40)(n=5)$ & $5(71)$ & $6(100)$ & $0.10^{\wedge}$ \\
\hline Deformity, $n(\%)$ & $4(12)$ & $0(0)$ & $6(86)$ & $1(20)(n=5)$ & $0.001 \wedge$ \\
\hline Neuropathy, n (\%) & $0(0)$ & $4(67)$ & $5(71)$ & $1(16.7)$ & $<0.001 \wedge$ \\
\hline Mild or moderate PAD, $n(\%)$ & $0(0)$ & $4(67)$ & $2(29)$ & $3(50)$ & $<0.001 \wedge$ \\
\hline Inappropriate footwear, n (\%) & $26(90)(n=29)$ & $5(83)$ & $5(71)$ & $5(83.3)$ & $0.52^{\wedge}$ \\
\hline Podiatry assessment, $n$ (\%) & $2(6)$ & $1(17)$ & $0(0)$ & $5(83)$ & $<0.001 \wedge$ \\
\hline FAC admission (median, [IQR]) & $3[2-3](n=27)$ & $2[0-3.3]$ & $1[0-3]$ & $2[0-3.3]$ & $0.84^{\#}$ \\
\hline SPPB (median, [IQR]) & $3[0-5](n=32)$ & $0[0-6](n=5)$ & $0[0-5]$ & $1[0-5.3]$ & $0.79^{\#}$ \\
\hline Katz ADL (median, [IQR]) & $2[1-4]$ & $1.5[0.8-3.8]$ & $1[1-3]$ & $2[0.8-2.5]$ & $0.31^{\#}$ \\
\hline iADL (median, [IQR]) & $1[1-2]$ & $2[0-3.3]$ & $1[1-3]$ & $1[0-3]$ & $0.12^{\#}$ \\
\hline MST (median, [IQR]) & $0[0-2]$ & $1.5[0-2.3]$ & $2[2-3]$ & $1[0-3](n=5)$ & $0.11^{\#}$ \\
\hline Braden scale (median, [IQR]) & 18 [17-20] & $16[15.5-20.3]$ & 17 [15-19] & 18 [17.5-18] & $0.48^{\#}$ \\
\hline CIRS (median, [IQR]) & $1.8[1.5-2.4]$ & $2.3[1.7-2.4]$ & $1.9[1.7-2]$ & $1.8[1.3-2]$ & $0.56^{\#}$ \\
\hline CFS (median, [IQR]) & $6[4-7](n=31)$ & $6.5[4.5-7](n=4)$ & $6[5-6.3](n=6)$ & $6.5[5-7]$ & $0.42^{\#}$ \\
\hline $\begin{array}{l}\text { Length of stay, geriatric rehabilitation, } \\
\text { days (median, }[\mathrm{QQR}] \text { ) }\end{array}$ & $15.2[8-22.1]$ & $27.1[12.7-37.7]$ & $25.8[12.5-32.8]$ & $24.5[14.5-27.7]$ & $0.1^{\#}$ \\
\hline Discharged home, $n$ (\%) & $23(70)$ & $4(67)$ & $4(57)$ & $2(33)$ & $0.41 \wedge$ \\
\hline Mortality, n (\%) & $2(15)$ & $0(0)$ & $0(0)$ & $1(17)$ & $0.59 \wedge$ \\
\hline
\end{tabular}

Group comparisons: ^Fisher's exact test, "Kruskal-Wallis $\mathrm{H}$ test

Abbreviations: $A D L$ Activities of Daily Living, BMI Body Mass Index, CFS Clinical Frailty Scale, CIRS Cumulative Illness Rating Scale, FAC Functional Ambulation Classification, $i A D L$ Instrumental Activities of Daily Living, IQR Interquartile range, MST Malnutrition Screening Tool, $P A D$ Peripheral Arterial Disease, SPPB Standardised Physical Performance Battery 
impairment in older adults on sub-acute wards [43]. Differences in training and clinical experience, the small sample size and the use of different assessment forms by researchers and hospital podiatrists may also have contributed to these findings. Nevertheless, the poor inter-rater reliability for these risk factors highlights the difficulty for non-podiatrist clinicians identifying at risk patients.

Risk of malnutrition was higher and length of stay on the Geriatric Rehabilitation ward was longer for patients with foot disease, at risk and high risk feet. There was no difference in Cumulative Illness Rating Scale or Clinical Frailty Scale between the groups, suggesting that this is not due to overall ill-health. The difference in length of stay may be explained by differences in nutritional status, as malnutrition is associated with longer length of hospital stay [44]. Malnutrition is a risk factor for pressure injuries, and nutritional interventions are recommended in prevention and treatment of pressure injuries [45]. Although two thirds of cases of foot disease in this cohort were pressure injuries, there was no difference in Braden scale between the foot disease group and other groups. A previous study also noted that the Braden scale under-estimates risk of foot pressure injury [46]. Risk of malnutrition may be useful to identify at risk patients for podiatry assessment. Although previous studies have shown associations between foot problems (particularly foot pain) $[2,47]$ and foot disease [48] and poorer physical function, this study did not identify any differences in physical function based on foot disease or foot disease risk factors.

The rate of foot disease in this cohort is similar to other studies in sub-acute populations in Scotland and Australia that reported prevalence rates of 15\% [17] and $12 \%$ [20] respectively. Diabetes-related foot disease is well recognised and improved outcomes have been achieved in recent years with interdisciplinary care [49], however in this cohort a minority of patients with foot disease and foot disease risk factors were diagnosed with diabetes. This is consistent with other studies of older adults [1, 17, 50]. Numerous other chronic medical conditions are associated with foot disease, such as osteoarthritis [51], chronic renal failure [52], gout [53] and rheumatoid arthritis [54]. Changes to the foot in addition to increased prevalence of chronic medical conditions with age $[2,55]$ are the likely cause of high rates of non-diabetes related foot disease in this population.

Use of inappropriate footwear was very common in this cohort and similar rates have been reported by other inpatient and outpatient studies of older adults $[17,56$, 57]. Footwear interventions have been shown to improve foot pain and function [58, 59]. Multifaceted podiatry intervention, including footwear advice and provision of orthotics, has been shown to reduce the risk of falls, however footwear advice alone has not [26]. Improving footwear is recognised to be a difficult task: low adherence rates for recommended footwear have been reported, mostly due to the cost and aesthetics of appropriate footwear [60].

Given the high prevalence of foot disease, foot disease risk factors and inappropriate footwear, as well as evidence for reduced falls [26] and foot pain [61, 62] from outpatient podiatry intervention in older adults, routine podiatry assessment and intervention should be considered as part of the CGA in geriatric rehabilitation inpatients. An alternative approach to increase the rate of podiatry assessment and intervention in this population, based on this study's findings, would be to include peripheral arterial disease and risk of malnutrition as indicators for podiatry referral.

\section{Limitations}

The pragmatic approach of comparing researcher foot assessments using the QFDF with podiatry assessments using the hospital assessment tool may have affected inter-rater reliability measures due to differences in documentation of foot deformity and footwear. Use of the QFDF for foot assessments may have underestimated the prevalence of foot problems, given that single foot deformities and integumentary problems are not captured with this assessment. The study was conducted in late summer, which may have impacted the prevalence of foot disease: studies of diabetes related foot disease have found higher rates of infection and amputation in warmer months, whilst amputations in people without diabetes are most common in winter [63, 64]. The study sample size is also a limitation, particularly for examining associations between foot disease, foot disease risk factors and patient characteristics.

\section{Conclusion}

Foot disease, foot disease risk factors and inappropriate footwear are common in older adults admitted to geriatric rehabilitation wards although podiatry assessment and intervention is mostly limited to patients with foot disease. Assessment for peripheral arterial disease and risk of malnutrition may help to identify at risk patients for podiatry input. Interventional studies incorporating podiatrist assessment and intervention into CGA are needed.

\section{Supplementary Information}

The online version contains supplementary material available at https://doi. org/10.1186/s12877-021-02164-3.

Additional file 1: Appendix I. The Queensland Foot Disease Form [18]. Appendix II. Hospital specific podiatry assessment form (2 pages).

\section{Acknowledgments}

The authors thank the multidisciplinary team members involved in the RESORT cohort for their clinical work and the @AgeMelbourne team for their role in data collection. 


\section{Authors' contributions}

Study concept RKI, GD, ABM; Data collection RKI, EKL, EL; Manuscript development led by RKI with input from all authors. The authors read and approved the final manuscript.

\section{Funding}

None to declare.

\section{Availability of data and materials}

All data generated or analysed during this study are included in this published article.

\section{Declarations}

\section{Ethics approval and consent to participate}

This study was conducted in accordance with the Declaration of Helsinki and approved by the local ethics committee.

\section{Consent for publication}

Not applicable.

\section{Competing interests}

None to declare.

\section{Author details}

1Department of Medicine and Aged Care, @AgeMelbourne, The Royal Melbourne Hospital, The University of Melbourne, Melbourne, Victoria, Australia. ${ }^{2}$ Faculty of Pharmacy and Pharmaceutical Sciences, Monash University, Parkville, Australia. ${ }^{3}$ Eastern Health Clinical School, Monash Universityl, Box Hill, Victoria, Australia. ${ }^{4}$ Podiatry Department, The Royal Melbourne Hospital, Parkville, Victoria, Australia. ${ }^{5}$ Department of Human Movement Sciences, @AgeAmsterdam, Vrije Universiteit Amsterdam, Amsterdam Movement Sciences, Amsterdam, The Netherlands. ${ }^{6}$ Healthy Longevity Translational Research Program, Yong Loo Lin School of Medicine, National University of Singapore, Singapore; Centre for Healthy Longevity, National University Health System, Singapore, Singapore.

Received: 7 January 2021 Accepted: 18 March 2021

Published online: 01 April 2021

\section{References}

1. Lazzarini PA, Hurn SE, Kuys SS, Kamp MC, Ng V, Thomas C, et al. The silent overall burden of foot disease in a representative hospitalised population. Int Wound J. 2017;14(4):716-28. https://doi.org/10.1111/iwj.12683.

2. Rodriguez-Sanz D, Tovaruela-Carrion N, Lopez-Lopez D, Palomo-Lopez P, Romero-Morales C, Navarro-Flores E, et al. Foot disorders in the elderly: a mini-review. Dis-a-Month: DM. 2018;64(3):64-91. https://doi.org/10.1016/j. disamonth.2017.08.001.

3. Menz HB, Auhl M, Spink MJ. Foot problems as a risk factor for falls in community-dwelling older people: a systematic review and meta-analysis. Maturitas. 2018;118:7-14. https://doi.org/10.1016/..maturitas.2018.10.001.

4. Katsambas A, Abeck D, Haneke E, van de Kerkhof P, Burzykowski T, Molenberghs $\mathrm{G}$, et al. The effects of foot disease on quality of life: results of the Achilles project. J Eur Acad Dermatol Venereol. 2005;19(2):191-5. https:// doi.org/10.1111/j.1468-3083.2004.01136.x.

5. López DL, Callejo González L, Losa Iglesias ME, Canosa JL, Sanz DR, Lobo CC, et al. Quality of life impact related to foot health in a sample of older people with hallux valgus. Aging Dis. 2016;7(1):45-52. https://doi.org/1 0.14336/AD.2015.0914

6. López-López D, Becerro-de-Bengoa-Vallejo R, Losa-Iglesias ME, PalomoLópez P, Rodríguez-Sanz D, Brandariz-Pereira JM, et al. Evaluation of foot health related quality of life in individuals with foot problems by gender: a cross-sectional comparative analysis study. BMJ Open. 2018;8(10):e023980. https://doi.org/10.1136/bmjopen-2018-023980.

7. López-López D, Martínez-Vázquez M, Losa-Iglesias ME, Calvo-Lobo C Rodríguez-Sanz D, Palomo-López P, et al. Foot health-related quality of life among elderly with and without lesser toe deformities: a case-control study. Patient Prefer Adher. 2018;12:251-5. https://doi.org/10.2147/PPA.S152269.

8. Muchna A, Najafi B, Wendel CS, Schwenk M, Armstrong DG, Mohler J. Foot problems in older adults (associations with incident falls, frailty syndrome, and sensor-derived gait, balance, and physical activity measures). J Am Podiatr Med Assoc. 2018;108(2):126-39. https://doi.org/10.7547/15-186.

9. Griffith L, Raina P, Wu H, Zhu B, Stathokostas L. Population attributable risk for functional disability associated with chronic conditions in Canadian older adults. Age Ageing. 2010;39(6):738-45. https://doi.org/10.1093/a geing/afq105.

10. Benvenuti F, Ferrucci L, Guralnik JM, Gangemi S, Baroni A. Foot pain and disability in older persons: an epidemiologic survey. J Am Geriatr Soc. 1995; 43(5):479-84. https://doi.org/10.1111/j.1532-5415.1995.tb06092.x.

11. Thorpe ER, Garrett KB, Smith AM, Reneker JC, Phillips RS. Outcome measure scores predict discharge destination in patients with acute and subacute stroke: a systematic review and series of meta-analyses. J Neurol Phys Ther. 2018;42(1):2-11. https://doi.org/10.1097/NPT.0000000000000211.

12. Cai Q, Salmon JW, Rodgers ME. Factors associated with long-stay nursing home admissions among the U.S. elderly population: comparison of logistic regression and the cox proportional hazards model with policy implications for social work. Soc Work Health Care. 2009;48(2):154-68. https://doi.org/1 0.1080/00981380802580588.

13. Gaugler JE, Duval S, Anderson KA, Kane RL. Predicting nursing home admission in the U.S: a meta-analysis. BMC Geriatr. 2007;7:13.

14. Chang P, Meaux T. Onychogryphosis: a report of ten cases. Skinmed. 2015; 13(5):355-9.

15. Möhrenschlager M, Wicke-Wittenius K, Brockow K, Bruckbauer H, Ring J. Onychogryphosis in elderly persons: an indicator of long-standing poor nursing care? Report of one case and review of the literature. Cutis. 2001; 68(3):233-5

16. Menant JC, Steele JR, Menz HB, Munro BJ, Lord SR. Effects of footwear features on balance and stepping in older people. Gerontology. 2008;54(1): 18-23. https://doi.org/10.1159/000115850.

17. Burns SL, Leese GP, McMurdo ME. Older people and ill fitting shoes. Postgrad Med J. 2002;78(920):344-6. https://doi.org/10.1136/pmj.78.920.344.

18. Lazzarini PA, Hurn SE, Kuys SS, Kamp MC, Ng V , Thomas C, et al. Direct inpatient burden caused by foot-related conditions: a multisite pointprevalence study. BMJ Open. 2016;6(6):e010811. https://doi.org/10.1136/ bmjopen-2015-010811.

19. Lazzarini PA, Hurn SE, Fernando ME, Jen SD, Kuys SS, Kamp MC, et al. Prevalence of foot disease and risk factors in general inpatient populations: a systematic review and meta-analysis. BMJ Open. 2015:5(11):e008544. https://doi.org/10.1136/bmjopen-2015-008544.

20. Earl BJ, Lazzarini PA, Kinnear EM, Cornwell PL. Prevalence of active foot disease and foot disease risk factors in a subacute inpatient rehabilitation facility: a cross-sectional prevalence study. J Foot Ankle Res. 2014;7(1):41. https://doi.org/10.1186/s13047-014-0041-x.

21. Lazzarini PA, Hurn SE, Kuys SS, Kamp MC, Ng V, Thomas C, et al. Foot complications in a representative Australian inpatient population. J Diab Res. 2017;2017:4138095.

22. Iseli RK, Lee EK, Lewis E, Duncan G, Maier AB. Foot disease and physical function in older adults: a systematic review and meta-analysis. Australas J Ageing. 2021;40(1):35-47.

23. Oh-Park M, Kirschner J, Abdelshahed D, Kim DDJ. Painful foot disorders in the geriatric population: a narrative review. Am J Phys Med Rehabil. 2019; 98(9):811-9. https://doi.org/10.1097/PHM.0000000000001239.

24. James K, Orkaby AR, Schwartz AW. Foot examination for older adults. Am J Med. 2020;134(1):30-5.

25. Tuttle CSL, Maier AB. Towards a biological geriatric assessment. Exp Gerontol. 2018;107:102-7. https://doi.org/10.1016/j.exger.2017.09.017.

26. Wylie G, Torrens C, Campbell P, Frost H, Gordon AL, Menz HB, et al. Podiatry interventions to prevent falls in older people: a systematic review and metaanalysis. Age Ageing. 2019;48(3):327-36. https://doi.org/10.1093/ageing/afy189.

27. Hatton AL, Rome K. Falls, footwear, and podiatric interventions in older adults. Clin Geriatr Med. 2019;35(2):161-71. https://doi.org/10.1016/..cger.201 8.12.001.

28. Parker SG, McCue P, Phelps K, McCleod A, Arora S, Nockels K, et al. What is comprehensive geriatric assessment (CGA)? An umbrella review. Age Ageing. 2018;47(1):149-55. https://doi.org/10.1093/ageing/afx166.

29. Welsh TJ, Gordon AL, Gladman JR. Comprehensive geriatric assessment--a guide for the non-specialist. Int J Clin Pract. 2014;68(3):290-3. https://doi. org/10.1111/ijcp.12313.

30. Arya R, Antonisamy B, Kumar S. Sample size estimation in prevalence studies. Indian J Pediatr. 2012;79(11):1482-8. https://doi.org/10.1007/s12098012-0763-3. 
31. Holden MK, Gill KM, Magliozzi MR. Gait assessment for neurologically impaired patients. Standards for outcome assessment. Phys Ther. 1986; 66(10):1530-9. https://doi.org/10.1093/ptj/66.10.1530.

32. Guralnik JM, Simonsick EM, Ferrucci L, Glynn RJ, Berkman LF, Blazer DG, et al. A short physical performance battery assessing lower extremity function: association with self-reported disability and prediction of mortality and nursing home admission. J Gerontol. 1994;49(2):M85-94. https://doi. org/10.1093/geronj/49.2.M85.

33. Katz S, Ford AB, Moskowitz RW, Jackson BA, Jaffe MW. Studies of illness in the aged. The index of ADL: a standardized measure of biological and psychosocial function. Jama. 1963;185(12):914-9. https://doi.org/10.1001/ja ma.1963.03060120024016.

34. Lawton MP, Brody EM. Assessment of older people: self-maintaining and instrumental activities of daily living. The Gerontologist. 1969;9(3):179-86. https://doi.org/10.1093/geront/9.3_Part_1.179.

35. Ferguson M, Capra S, Bauer J, Banks M. Development of a valid and reliable malnutrition screening tool for adult acute hospital patients. Nutrition. 1999; 15(6):458-64. https://doi.org/10.1016/S0899-9007(99)00084-2.

36. Bergstrom N, Braden B, Kemp M, Champagne M, Ruby E. Predicting pressure ulcer risk: a multisite study of the predictive validity of the Braden scale. Nurs Res. 1998;47(5):261-9. https://doi.org/10.1097/00006199-1 99809000-00005.

37. Linn BS, Linn MW, Gurel L. Cumulative illness rating scale. J Am Geriatr Soc. 1968;16(5):622-6. https://doi.org/10.1111/j.1532-5415.1968.tb02103.x.

38. Rockwood K, Song X, Macknight C, Bergman H, Hogan DB, McDowell I, et al. A global clinical measure of fitness and frailty in elderly people. Cmaj. 2005;173(5):489-95. https://doi.org/10.1503/cmaj.050051.

39. Menant JC, Steele JR, Menz HB, Munro BJ, Lord SR. Optimizing footwear for older people at risk of falls. J Rehabil Res Dev. 2008;45(8):1167-81. https:// doi.org/10.1682/JRRD.2007.10.0168.

40. McHugh ML. Interrater reliability: the kappa statistic. Biochem Med (Zagreb). 2012;22(3):276-82

41. Landis JR, Koch GG. The measurement of observer agreement for categorical data. Biometrics. 1977;33(1):159-74. https://doi.org/10.2307/2 529310.

42. Harris PA, Taylor R, Thielke R, Payne J, Gonzalez N, Conde JG. Research electronic data capture (REDCap)--a metadata-driven methodology and workflow process for providing translational research informatics support. J Biomed Inform. 2009;42(2):377-81. https://doi.org/10.1016/j.jbi.2008.08.010.

43. Clark AB, Reijnierse EM, Lim WK, Maier AB. Prevalence of malnutrition comparing the GLIM criteria, ESPEN definition and MST malnutrition risk in geriatric rehabilitation patients: RESORT. Clin Nutr. 2020;39(11):3504-11. https://doi.org/10.1016/j.clnu.2020.03.015.

44. Leiva Badosa E, Badia Tahull M, Virgili Casas N, Elguezabal Sangrador G, Faz Méndez C, Herrero Meseguer I, et al. Hospital malnutrition screening at admission: malnutrition increases mortality and length of stay. Nutr Hosp. 2017;34(4):907-13. https://doi.org/10.20960/nh.657.

45. Eglseer D, Hödl M, Lohrmann C. Nutritional management of older hospitalised patients with pressure injuries. Int Wound J. 2019;16(1):226-32. https://doi.org/10.1111/iwj.13016.

46. Scheepers J. Assessment and consideration of foot risk factors is essential for proactive prevention of hospital-acquired foot pressure injuries. Wounds Int. 2018;9(1):29-34.

47. Menz HB. Biomechanics of the ageing foot and ankle: a mini-review Gerontology. 2015:61(4):381-8. https://doi.org/10.1159/000368357.

48. McDermott MM, Greenland P, Liu K, Guralnik JM, Celic L, Criqui MH, et al. The ankle brachial index is associated with leg function and physical activity: the walking and leg circulation study. Ann Intern Med. 2002;136(12): 873-83. https://doi.org/10.7326/0003-4819-136-12-200206180-00008.

49. Barshes NR, Sigireddi M, Wrobel JS, Mahankali A, Robbins JM, Kougias P, et al. The system of care for the diabetic foot: objectives, outcomes, and opportunities. Diab Foot Ankle. 2013;4(1). https://doi.org/10.3402/ dfa.v4i0.21847.

50. Schwarzentraub PH, Raymond GA, Ball MJ, Bizzoco DL. Foot ulcers: a 54month retrospective study. J Foot Surg. 1991;30(5):437-42.

51. Roddy E, Menz HB. Foot osteoarthritis: latest evidence and developments. Ther Adv Musculoskelet Dis. 2018;10(4):91-103. https://doi.org/10.1177/1 $759720 \times 17753337$.

52. Otte J, van Netten JJ, Woittiez AJ. The association of chronic kidney disease and dialysis treatment with foot ulceration and major amputation. J Vasc Surg. 2015;62(2):406-11. https://doi.org/10.1016/j.jvs.2015.02.051.
53. Rome K, Erikson K, Otene C, Sahid H, Sangster K, Gow P. Clinical characteristics of foot ulceration in people with chronic gout. Int Wound J. 2016;13(2):209-15. https://doi.org/10.1111/iwj.12262.

54. Firth J, Waxman R, Law G, Nelson EA, Helliwell P, Siddle $H$, et al. The predictors of foot ulceration in patients with rheumatoid arthritis. Clin Rheumatol. 2014;33(5):615-21. https://doi.org/10.1007/s10067-013-2428-7.

55. Global Burden of Disease Study 2013 Collaborators. Global, regional, and national incidence, prevalence, and years lived with disability for 301 acute and chronic diseases and injuries in 188 countries, 1990-2013: a systematic analysis for the Global Burden of Disease Study 2013. Lancet. 2015; 386(9995):743-800.

56. Jessup RL. Foot pathology and inappropriate footwear as risk factors for falls in a subacute aged-care hospital. J Am Podiatr Med Assoc. 2007;97(3):213-7. https://doi.org/10.7547/0970213.

57. O'Rourke B, Walsh ME, Brophy R, Vallely S, Murphy N, Conroy B, et al. Does the shoe really fit? Characterising ill-fitting footwear among communitydwelling older adults attending geriatric services: an observational crosssectional study. BMC Geriatr. 2020;20(1):55. https://doi.org/10.1186/s12877020-1448-9.

58. Menz HB, Auhl M, Ristevski S, Frescos N, Munteanu SE. Effectiveness of offthe-shelf, extra-depth footwear in reducing foot pain in older people: a randomized controlled trial. J Gerontol A Biol Sci Med Sci. 2015;70(4):511-7. https://doi.org/10.1093/gerona/glu169.

59. Frecklington M, Dalbeth N, McNair P, Gow P, Williams A, Carroll M, et al. Footwear interventions for foot pain, function, impairment and disability for people with foot and ankle arthritis: a literature review. Semin Arthritis Rheum. 2018;47(6):814-24. https://doi.org/10.1016/j.semarthrit.2017.10.017.

60. Menz HB, Spink MJ, Landorf KB, Hill KD, Lord SR. Older people's perceptions of a multifaceted podiatric medical intervention to prevent falls. J Am Podiatr Med Assoc. 2013;103(6):457-64. https://doi.org/10.7547/1030457.

61. Araguas Garcia C, Corbi SF. Effect of debridement of plantar hyperkeratoses on gait in older people - an exploratory trial. Arch Gerontol Geriatr. 2018;78:7-13. https://doi.org/10.1016/j.archger.2018.05.017.

62. Balanowski KR, Flynn LM. Effect of painful keratoses debridement on foot pain, balance and function in older adults. Gait Posture. 2005;22(4):302-7. https://doi.org/10.1016/j.gaitpost.2004.10.006.

63. Leung $H B$, Ho YC, Wong WC, Guerin J. Seasonal variations in non-traumatic major lower limb amputation in Hong Kong Chinese diabetic patients. Hong Kong Med J. 2007;13(5):379-81.

64. Armstrong DG, Lavery LA, van Houtum WH, Harkless LB. Seasonal variations in lower extremity amputation. J Foot Ankle Surg. 1997;36(2):146-50. https://doi.org/10.1016/\$1067-2516(97)80062-2.

\section{Publisher's Note}

Springer Nature remains neutral with regard to jurisdictional claims in published maps and institutional affiliations.
Ready to submit your research? Choose BMC and benefit from:

- fast, convenient online submission

- thorough peer review by experienced researchers in your field

- rapid publication on acceptance

- support for research data, including large and complex data types

- gold Open Access which fosters wider collaboration and increased citations

- maximum visibility for your research: over $100 \mathrm{M}$ website views per year

At $\mathrm{BMC}$, research is always in progress.

Learn more biomedcentral.com/submissions 